\title{
BMJ Open Quality of life in adults with multiple sclerosis: a systematic review
}

\author{
Irene Gil-González (D) , ${ }^{1}$ Agustín Martín-Rodríguez, ${ }^{1}$ Rupert Conrad, ${ }^{2}$ \\ María Ángeles Pérez-San-Gregorio ${ }^{1}$
}

To cite: Gil-González I, Martín-Rodríguez A, Conrad R, et al. Quality of life in adults with multiple sclerosis: a systematic review. BMJ Open 2020;10:e041249. doi:10.1136/ bmjopen-2020-041249

- Prepublication history and supplemental material for this paper are available online. To view these files, please visit the journal online (http://dx. doi. org/10.1136/bmjopen-2020041249).

IG-G, AM-R, RC and MÁP-S-G contributed equally.

Received 03 June 2020 Revised 04 November 2020 Accepted 04 November 2020

Check for updates

(C) Author(s) (or their employer(s)) 2020. Re-use permitted under CC BY-NC. No commercial re-use. See rights and permissions. Published by BMJ.

${ }^{1}$ Personality, Assessment, and Psychological Treatment, University of Seville, Seville, Spain

${ }^{2}$ Department of Psychosomatic Medicine and Psychotherapy, University Hospital Bonn, Bonn, Germany

Correspondence to

Irene Gil-González; igil2@us.es

\begin{abstract}
Objective In recent years, quality of life (QoL) in multiple sclerosis (MS) has been gaining considerable importance in clinical research and practice. Against this backdrop, this systematic review aimed to provide a broad overview of clinical, sociodemographic and psychosocial risk and protective factors for QoL in adults with MS and analyse psychological interventions for improving QoL.

Method The literature search was conducted in the Scopus, Web of Science and ProQuest electronic databases. Document type was limited to articles written in English, published from January 1, 2014, to January 31, 2019. Information from the selected articles was extracted using a coding sheet and then qualitatively synthesised.

Results The search identified 4886 records. After duplicate removal and screening, 106 articles met the inclusion and exclusion criteria for qualitative synthesis and were assessed for study quality. Disability, fatigue, depression, cognitive impairment and unemployment were consistently identified as QoL risk factors, whereas higher self-esteem, self-efficacy, resilience and social support proved to be protective. The review analysed a wide spectrum of approaches for QoL psychological intervention, such as mindfulness, cognitive behavioural therapy, self-help groups and self-management. The majority of interventions were successful in improving various aspects of QoL.
\end{abstract}

Conclusion Adequate biopsychosocial assessment is of vital importance to treat risk and promote protective factors to improve QoL in patients with MS in general care practice.

\section{INTRODUCTION}

The Constitution of the WHO declares health to be '....a state of complete physical, mental and social well-being and not merely the absence of disease or infirmity'. ${ }^{1}$ Quality of life (QoL) is a multidimensional concept that encompasses the domains included in this definition of health. ${ }^{23}$ Its introduction in medical literature dates back to $1960,{ }^{4}$ with its importance continuously growing to date. ${ }^{5}$

Multiple sclerosis (MS) is a chronic neurodegenerative condition characterised by a wide range of symptoms and a highly unpredictable prognosis, which can severely affect patient QoL. ${ }^{6-8}$ Patients with MS tend to report lower QoL than the general

\section{Strengths and limitations of this study}

This is the first systematic review of risk factors and psychological intervention for quality of life in multiple sclerosis for over a decade.

- A comprehensive and robust search strategy and strict inclusion criteria were employed to cover all the relevant evidence.

- Careful standardised risk of bias was assessed in all 106 studies included.

- Due to heterogeneity of the studies, only qualitative synthesis of results was possible.

- The huge number of publications made it necessary to limit the time span to the 5 -year period from January 1,2014 , to January $31,2019$.

population. ${ }^{9-12}$ This diminished QoL may be due to their impaired functioning in daily living, more so if the help of caregivers is required, impeding family relations, work and social dynamics. ${ }^{13} 14$ The impact of MS on QoL can be affected by numerous diseaserelated factors, such as disability level or MS type, and individual factors such as social support, education, age or employment. ${ }^{15-18}$

Identification of risk and protective factors is a key point in implementing strategies to improve patient's QoL. ${ }^{7}$ In this context, all influences must be considered to contribute to QoL in MS. ${ }^{79}$ In addition to providing practitioners with useful information on the impact of symptoms and therapy on the patient's life, QoL is also an indicator of treatment success and a predictor of disease progression. ${ }^{20-22}$

In view of its relevance in healthcare research, the need to compile and condense available scientific evidence on the subject is urgent. Against this backdrop, this systematic review gives a comprehensive overview of risk and protective factors related to QoL in MS as well as relevant psychological interventions. The growing number of studies on this subject ${ }^{22}$ provides a vast amount of data, which due to the inconsistency of findings needs careful assessment to come to evidencebased conclusions. 


\section{METHODOLOGY}

This systematic review was performed following the Preferred Reporting Items for Systematic Reviews and Meta-Analyses (PRISMA) guidelines. ${ }^{23}$ As a review of prior publications, ethical approval (or informed consent) was unnecessary. A review protocol is available from the corresponding author on request.

\section{Search strategy}

The systematic search focused on journal articles published between January 1, 2014, and January 31, 2019. The Scopus, Web of Science and ProQuest databases were searched in February and March 2019. The key words used were ('multiple sclerosis') AND ('quality of life' OR 'health-related quality of life' OR 'well-being' OR 'well-being' OR 'life satisfaction'). The search terms were intentionally broad to ensure wide coverage of the literature. The search field was limited to 'title/abstract' and language was limited to 'English'. The complete research string is reported under online supplemental file 1.

There is no published systematic review on this topic in the Cochrane Library.

\section{Study selection}

First, title and abstract were screened to identify suitable articles for full text review. The screening process was performed independently by two researchers. Any disagreement about study selection was resolved by consensus with a third reviewer.

Inclusion criteria were the following:

1. Studies primarily focusing on QoL determinants and psychological intervention to improve it.

2. Study participants aged over 18 years with a confirmed MS diagnosis.

The following exclusion criteria were applied:

1. Non-psychological intervention.

2. Not primary research studies (systematic reviews, metaanalyses, protocols and clinical guidelines were excluded).

3. Studies on the development and validation of QoL measurement instruments.

4. QoL risk or intervention studies for healthy behaviour, cognitive rehabilitation, physical activity or pharmacological treatment.

5. Studies on comorbidity with another illness or mental health diagnosis.

6. Sample selection based on a special condition (eg, only employees or patients with MS under certain pharmacological treatment).

7. Studies not using a validated QoL measurement tool.

\section{Quality assessment}

The methodological quality of the studies was appraised with a well-established standardised 12-item checklist, ${ }^{24}$ in which every item represents a methodological feature: inclusion/exclusion criteria, methodology/ design, attrition rate, attrition between-groups, exclusions after, follow-up, occasion of measurements, pre/ post measures, dependent variables, control techniques, construct definition and imputing missing data. The codification criteria proposed by the checklist authors was used. No article was excluded from quality appraisal.

\section{Data abstraction}

Data were extracted from selected articles based on a previously designed coding sheet. The pilot study was approved by consensus. The information extracted included: title, authors and publication year, country (city), design, sample characteristics, study variables and measurement tools, main results and conclusions. After extraction, the information was independently reviewed by two authors to avoid errors or omitting data.

A meta-analysis was not possible due to the heterogeneity of study designs and outcomes, so a narrative synthesis was undertaken.

\section{RESULTS}

\section{Literature screening}

A total of 4886 articles were initially identified from Scopus, Web of Science and ProQuest. After removal of duplicates and abstract analysis, 188 studies were eligible for full text review. Finally, 106 were selected for the narrative analysis. The selection process is detailed below in a PRISMA flow diagram (figure 1).

\section{Methodological quality}

Methodological quality scores using the 12-item checklist are summarised in table 1 .

\section{Study characteristics}

The articles included were analysed by their primary and secondary outcomes. Seventy studies analysed QoL risk and protective factors (table 2), 11 focused on the development of QoL at different ages and times in the disease (table 3) and 25 studied the effect of psychological intervention on QoL in MS (table 4).

All the articles included employed standardised and validated QoL measurement instruments; 64 studies evaluated QoL with a generic measure and 50 studies made use of a disease-specific measure. The Short Form Health Survey 36 (SF-36) was mainly used $(\mathrm{n}=29)$ as a generic measure and Multiple Sclerosis Quality of Life-54 (MSQoL-54) ( $\mathrm{n}=28)$ as a diseasespecific measure. Finally, 11 studies used more than one measure to evaluate QoL. The study designs were mostly cross-sectional $(n=74)$, and sample sizes ranged from 7 to 74451 participants.

The main findings of the articles are summarised below.

\section{Risk and protective MS QoL factors}

Factors influencing MS patient's QoL are summarised in table 2. 


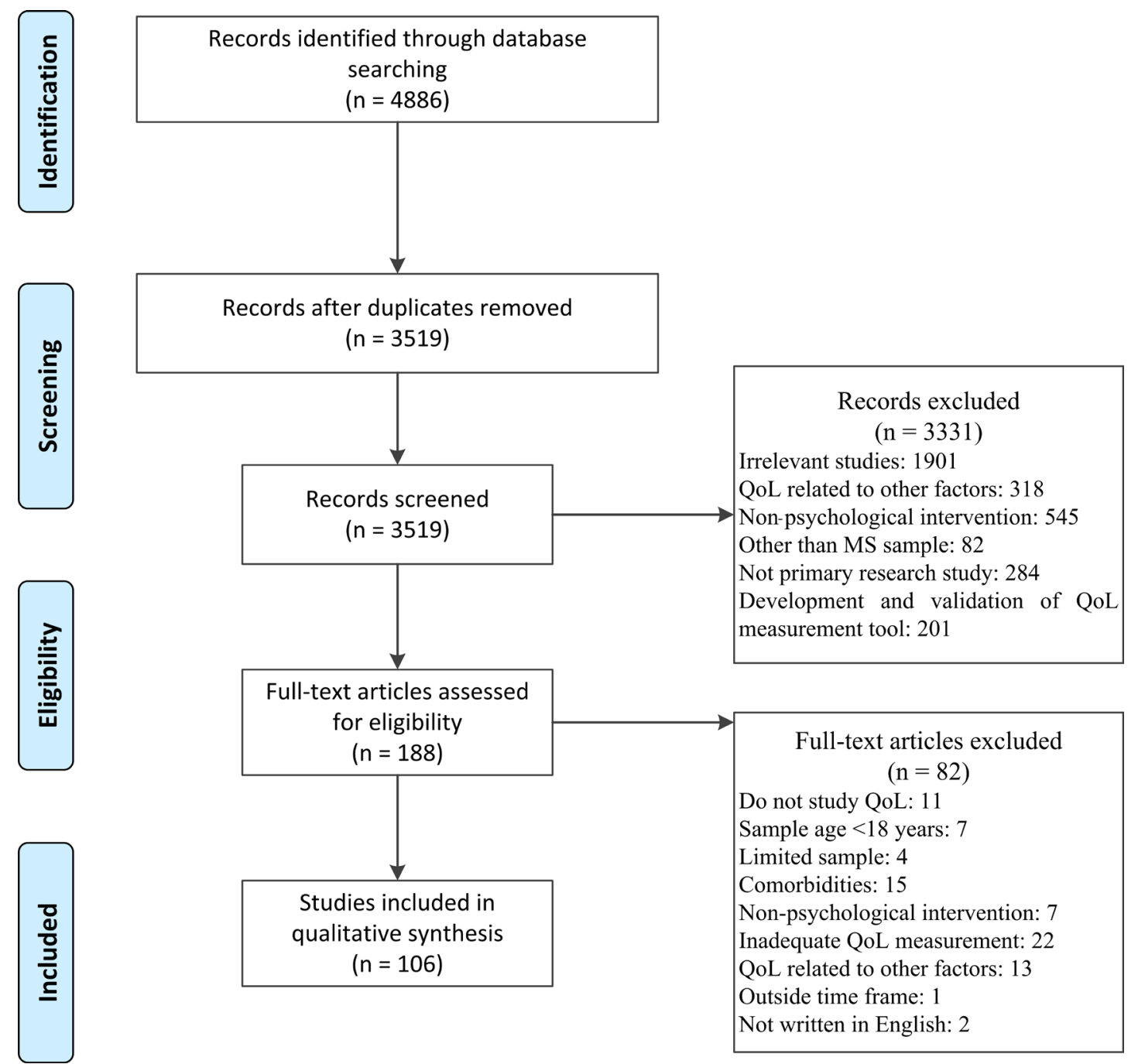

Figure 1 Preferred Reporting Items for Systematic Reviews and Meta-Analyses (PRISMA) flow diagram of selection process. MS, multiple sclerosis; QoL, quality of life.

\section{Clinical factors}

Functional impairment as assessed by the Expanded Disability Status Scale (EDSS) level was one of the leading causes of diminished QoL. ${ }^{25-35}$ Disease duration, ${ }^{30} 31$ progressive type, ${ }^{26} 36{ }^{37}$ progressive MS onset ${ }^{38}$ and relapses in the last 3 months were further relevant factors negatively affecting QoL. ${ }^{26}$

Several studies found a significant association between the severity and number of symptoms and the decline of QoL in MS ${ }^{33}{ }^{37-41}$ Fatigue was identified as a main risk factor. $^{28} 29394042-52$

A number of articles stated the importance of sensory $^{53} 54$ and motor ${ }^{49} 525455$ dysfunction on QoL, including paralysis, walking difficulties, balance, stiffness and spasms as motor problems, specifically emphasising pain 343950515556 and spasticity, ${ }^{45} 58$ and low sensory sensitivity and sensation avoidance as sensory problems.

Bladder dysfunction, ${ }^{34} 5960$ bowel dysfunction, ${ }^{34}$ sexual, ${ }^{60-62}$ and sleeping ${ }^{34} 39486364$ problems contributed to deterioration of QoL.
A diversity of cognitive impairments, for instance, cognitive fatigue, memory loss and planning/organisational dysfunction, were recognised as risk factors by a number of studies. ${ }^{39} 50525365-67$ Sgaramella et a $l^{68}$ showed that maintaining executive functioning was a protective factor of QoL. This was also the only study on the important subject of cognitive reserve and QoL.

\section{Psychosocial factors}

\section{Emotional symptoms}

Some studies reported the beneficial effect of emotional stability on QoL ${ }^{69}$ and the harmful effect of emotional problems. ${ }^{52} 70$ The emotional symptom studied most was depression $282932343539405155656971-75$ followed by anxiety. ${ }^{39} 40516971-7476$ Both symptoms were confirmed as risk factors for QoL in MS. Similarly, high levels of perceived stress, ${ }^{37} 4041$ anger expression-in ${ }^{74}$ and apathy ${ }^{29}$ were identified as factors related to emotional regulation negatively affecting QoL in MS. 
The role of personality domains was explored in several studies. Cyclothymic and depressive temperament were associated with a lower QoL in MS, in contrast to hyperthymic temperament, which was associated with higher QoL. ${ }^{77}$ Another study recognised extraversion as a personality trait related to higher QoL levels. ${ }^{69}$ Cioncoloni et $a b^{34}$ recognised introverted personality as a risk factor for QoL in MS, and finally, type D personality was another relevant factor. ${ }^{78}$

\section{Coping strategies}

Results with regard to coping strategies were consistent. Active coping, problem resolution, planning problem solving, cognitive positive restructuring, emotional and instrumental social support, emotional expression, acceptance and growth were related to a higher QoL in MS. ${ }^{51} 71$ 79-82 In addition, Grech et $a l^{80}$ found a similar connection with restrained coping, Strober ${ }^{51}$ with humour and Mikula et $a l^{82}$ with stopping unpleasant emotion coping strategies. On the contrary, problem avoidance, ${ }^{71}{ }^{81}$ behavioural disengagement, ${ }^{51}{ }^{80}$ distancing, ${ }^{81}$ self-distraction, ${ }^{79}$ denial, ${ }^{5179}$ emotion-focused and venting coping strategies, ${ }^{80}$ social withdrawal, ${ }^{71}$ wishful thinking, ${ }^{71}$ self-criticism, $^{71} 81$ suppression $^{80}$ and self-controlling $\operatorname{coping}^{70}$ were associated with lower QoL.

Coping strategies were also identified as relevant mediator variables. Problem-focused, emotion-focused and stopping unpleasant emotion coping strategies were partial mediators between fatigue ${ }^{83}$ or type D personality $^{84}$ and QoL as measured by the Mental Composite Score (MCS).

\section{Other psychological factors}

According to Van Damme $e t a l,{ }^{85}$ acceptance of the illness is a protective factor for QoL. The role of flexible adjustment and tenacious goal pursuit in achieving personally blocked goals was not as clear, although their findings showed a trend towards a positive relationship.

Resilience was confirmed as a protective factor of QoL in MS. ${ }^{2786}$ Moreover, Koelmel et $a l^{87}$ highlighted its role as a mediator variable in the relationship between social support and MCS.

High levels of self-efficacy, ${ }^{5188}$ self-esteem, ${ }^{88}$ illness identity $^{88}$ and sense of coherence ${ }^{89}$ correlated with higher QoL, and self-esteem mediated in the relationship of social support with MCS. ${ }^{90}$ Ultimately, cognitive fusion, the extent to which people feel fused with or attached to their thoughts, mediated the relationship between stigma and QoL in MS. ${ }^{91}$

\section{Social factors}

Social support ${ }^{92}$ and participation ${ }^{93}$ were positively related with QoL. Several mediators in this relationship were mentioned above.

\section{Demographic factors}

Employment was found to be the leading sociodemographic factor influencing QoL. Several studies 


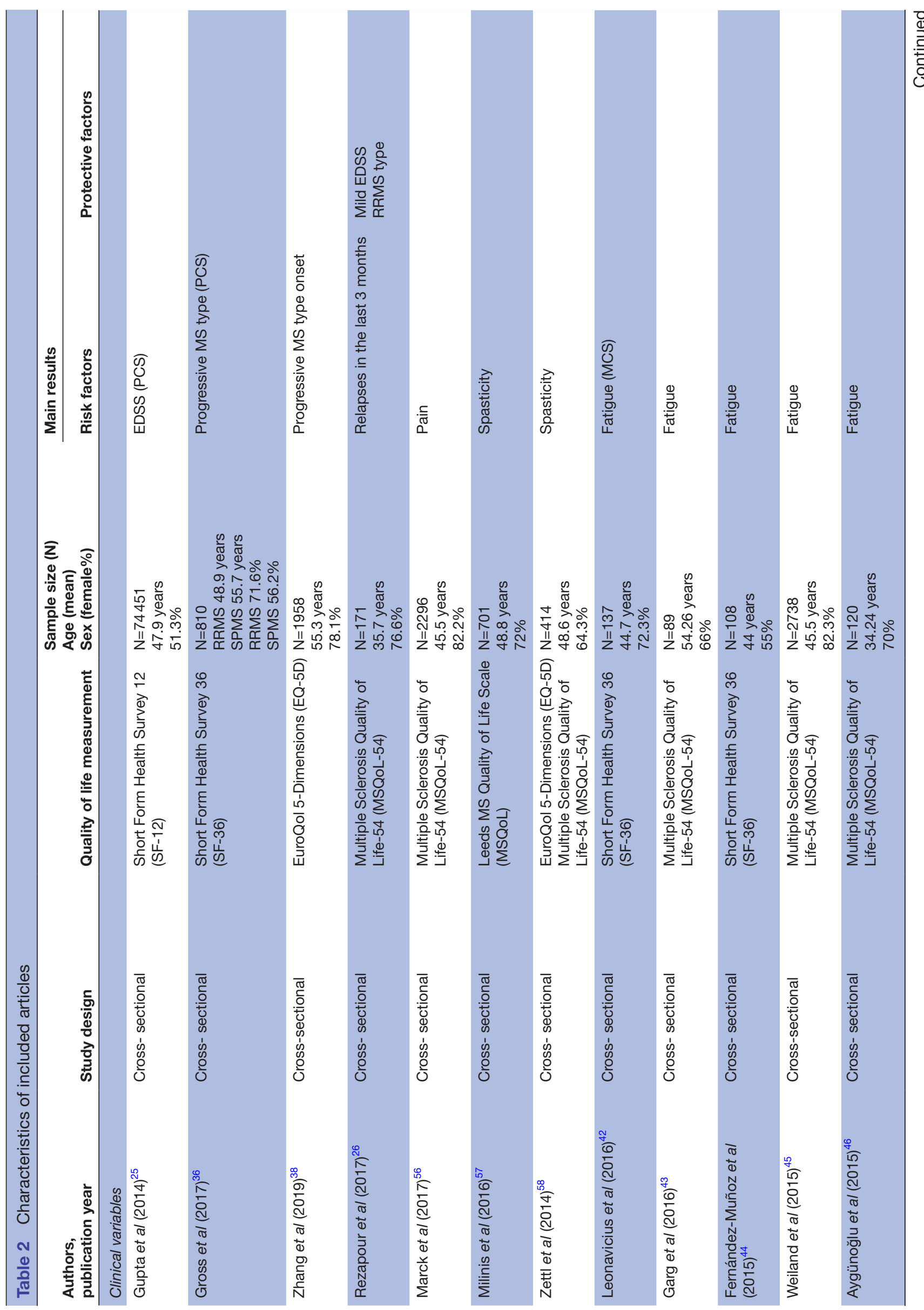



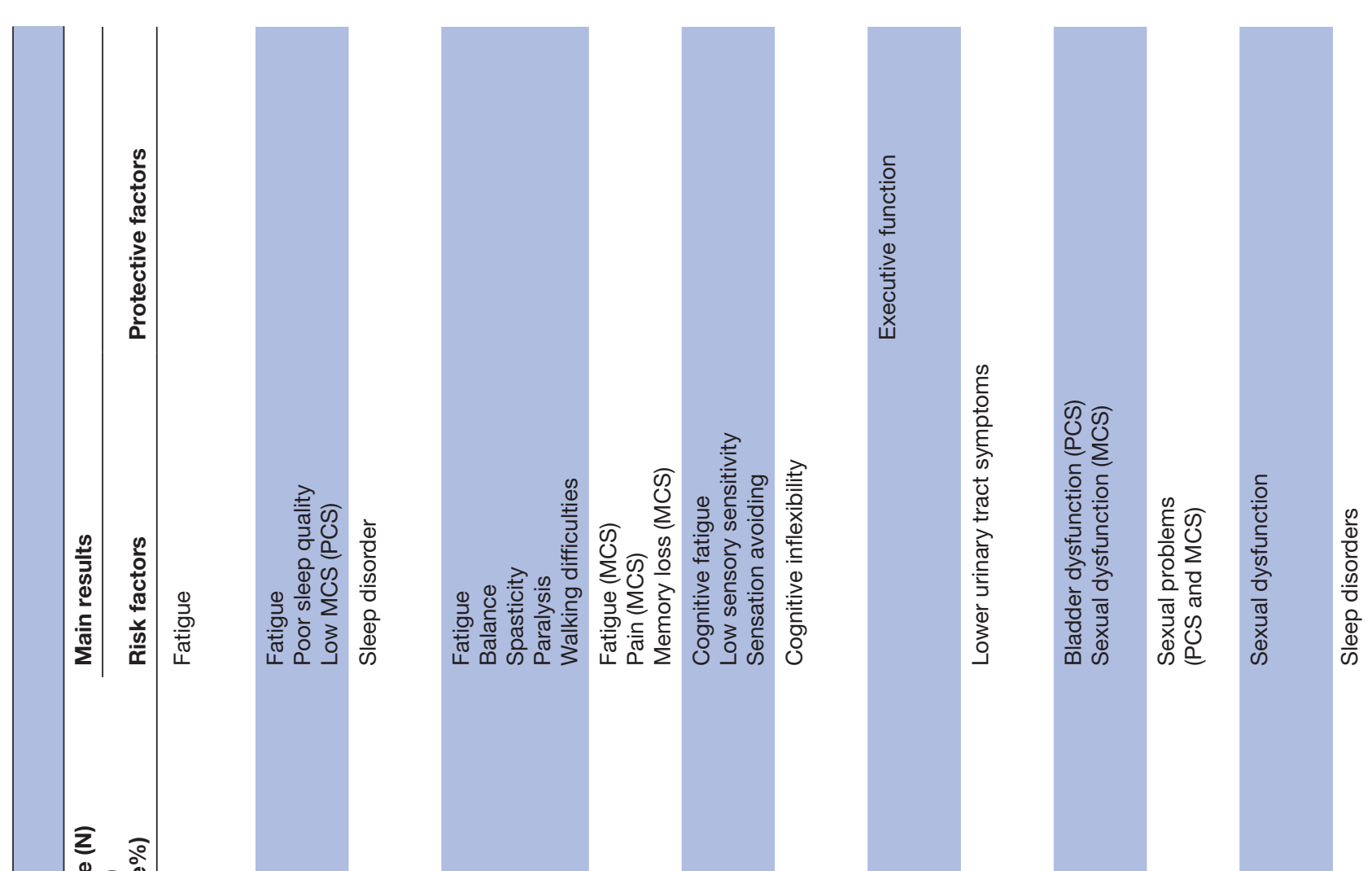

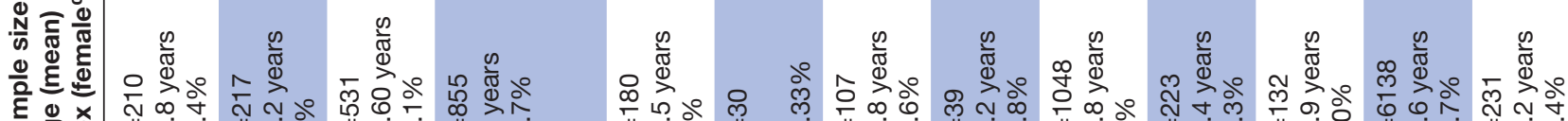

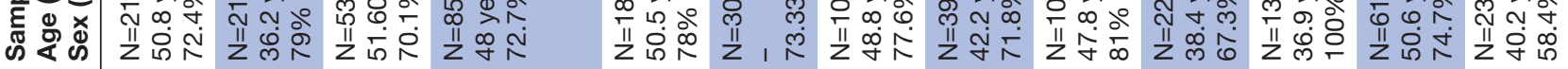

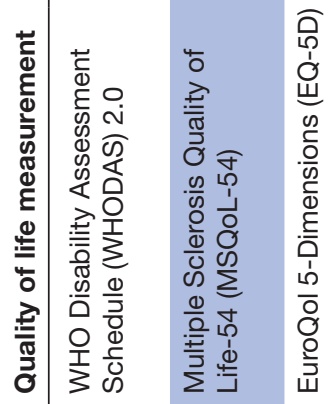
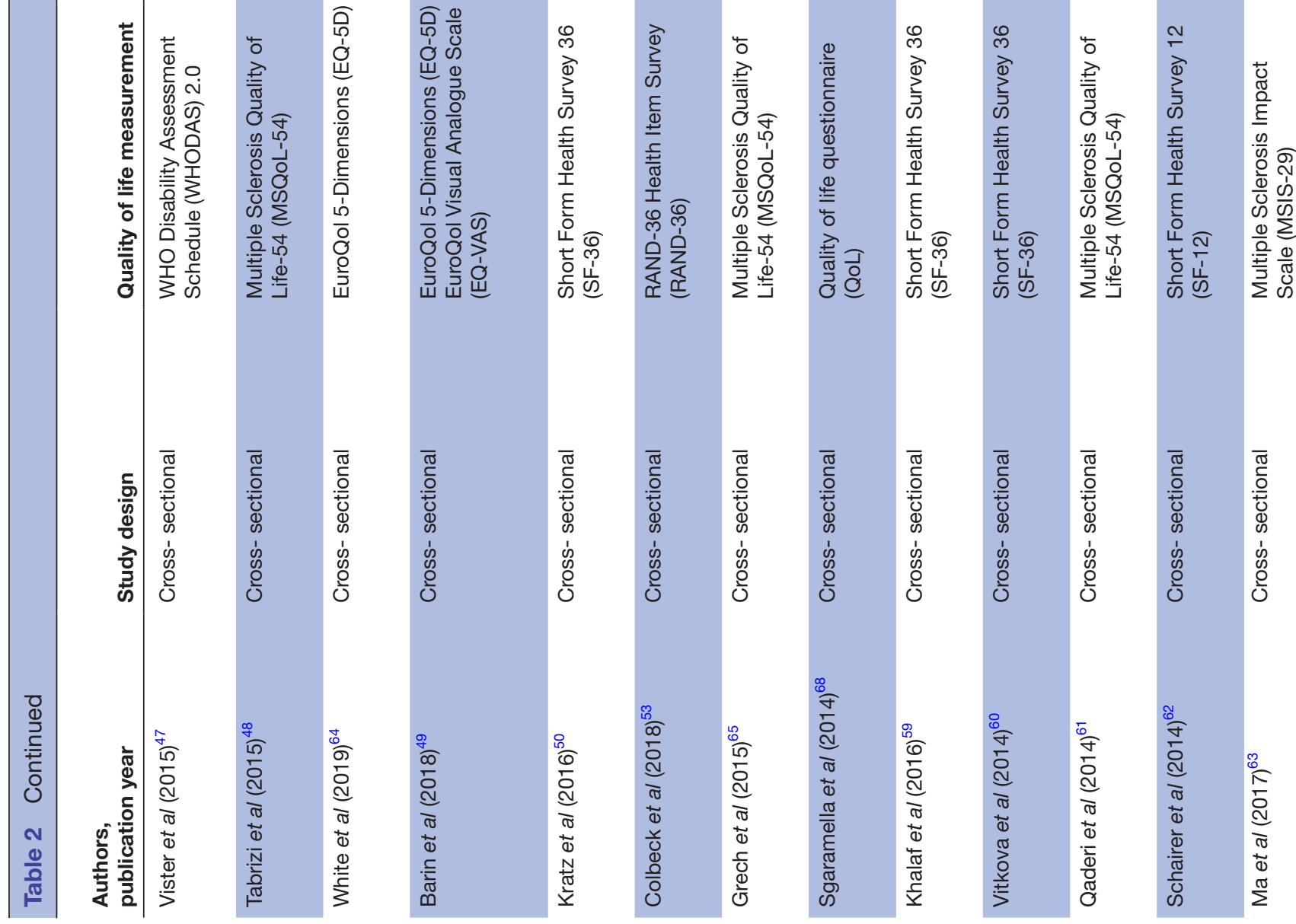


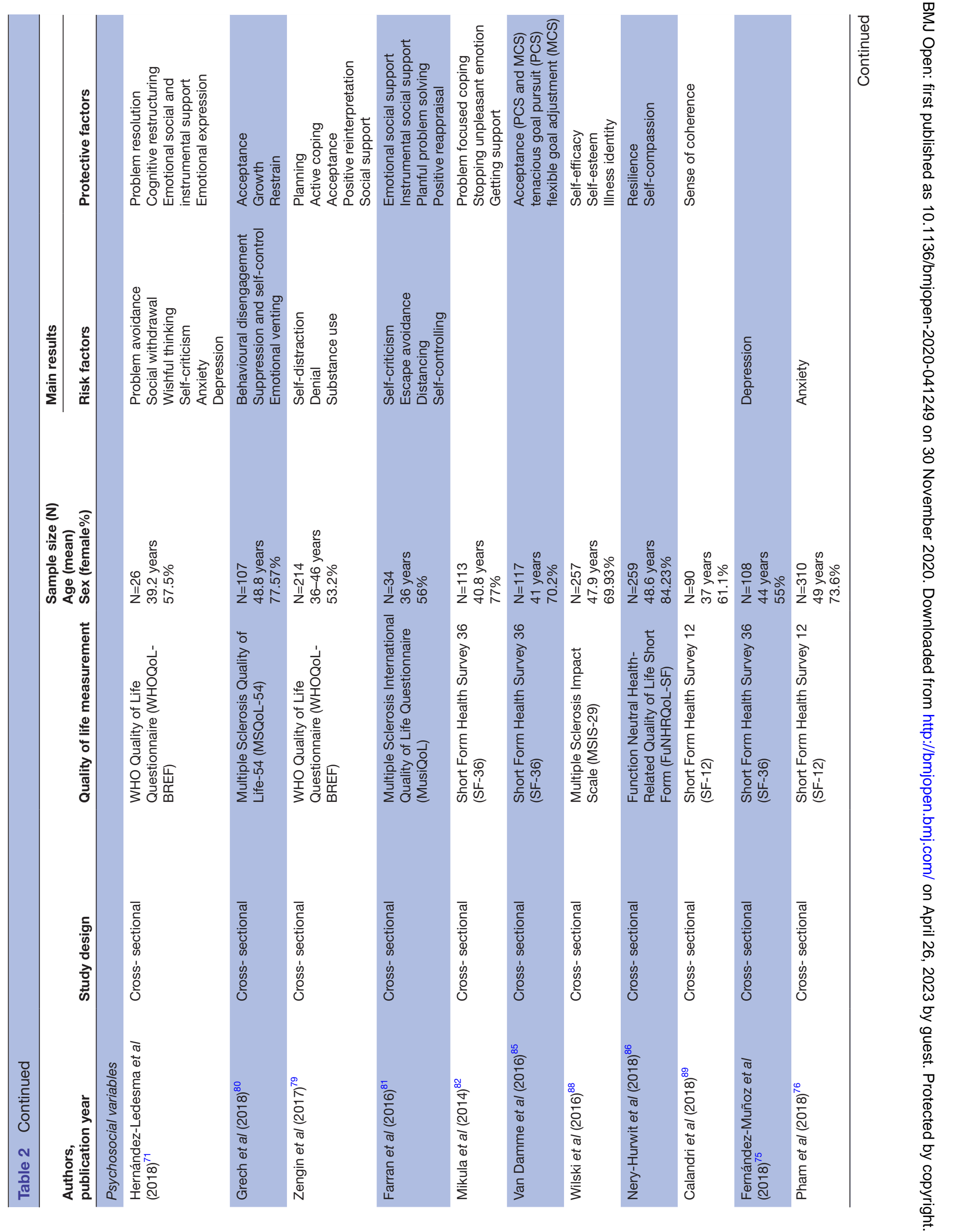




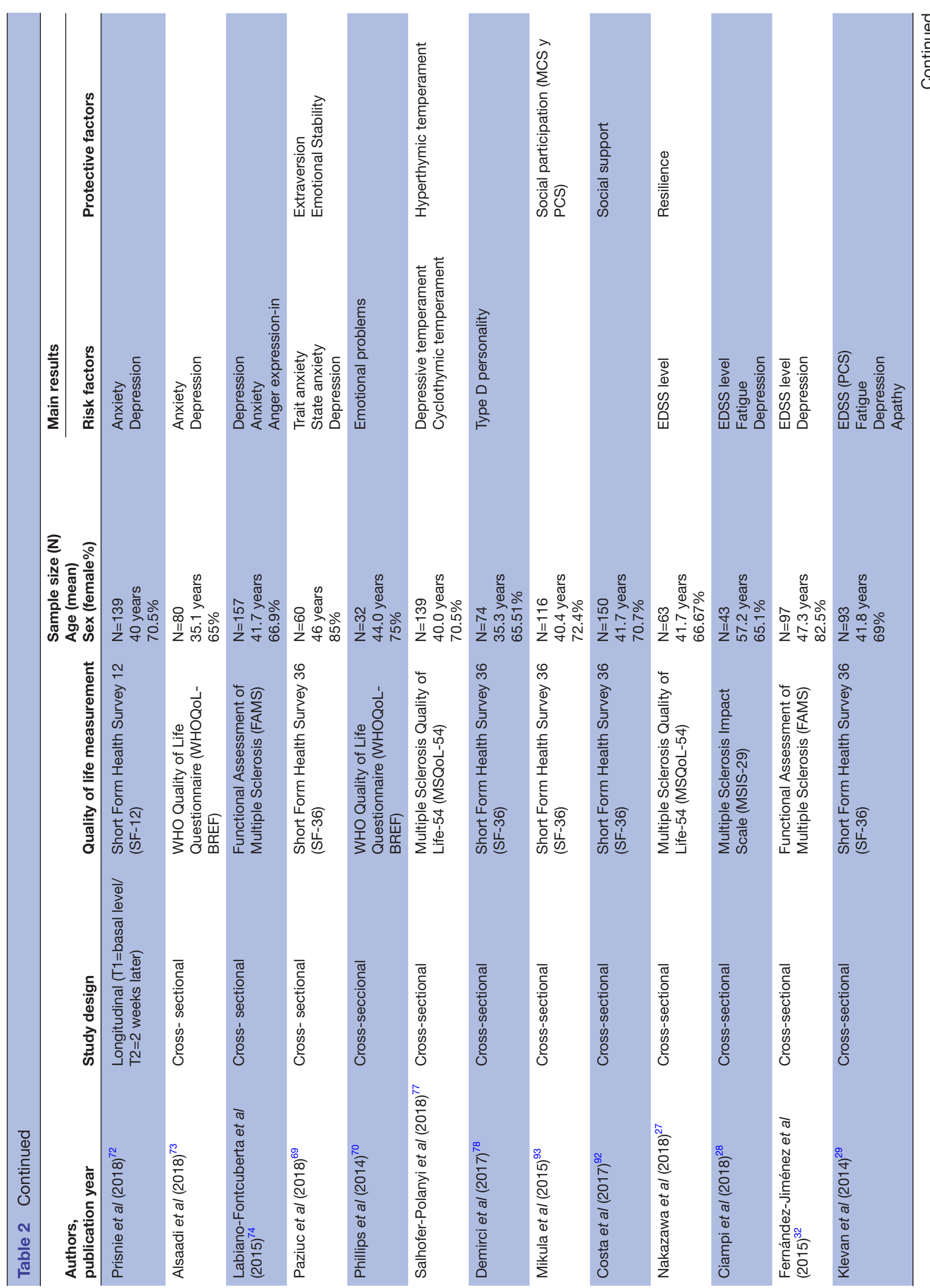




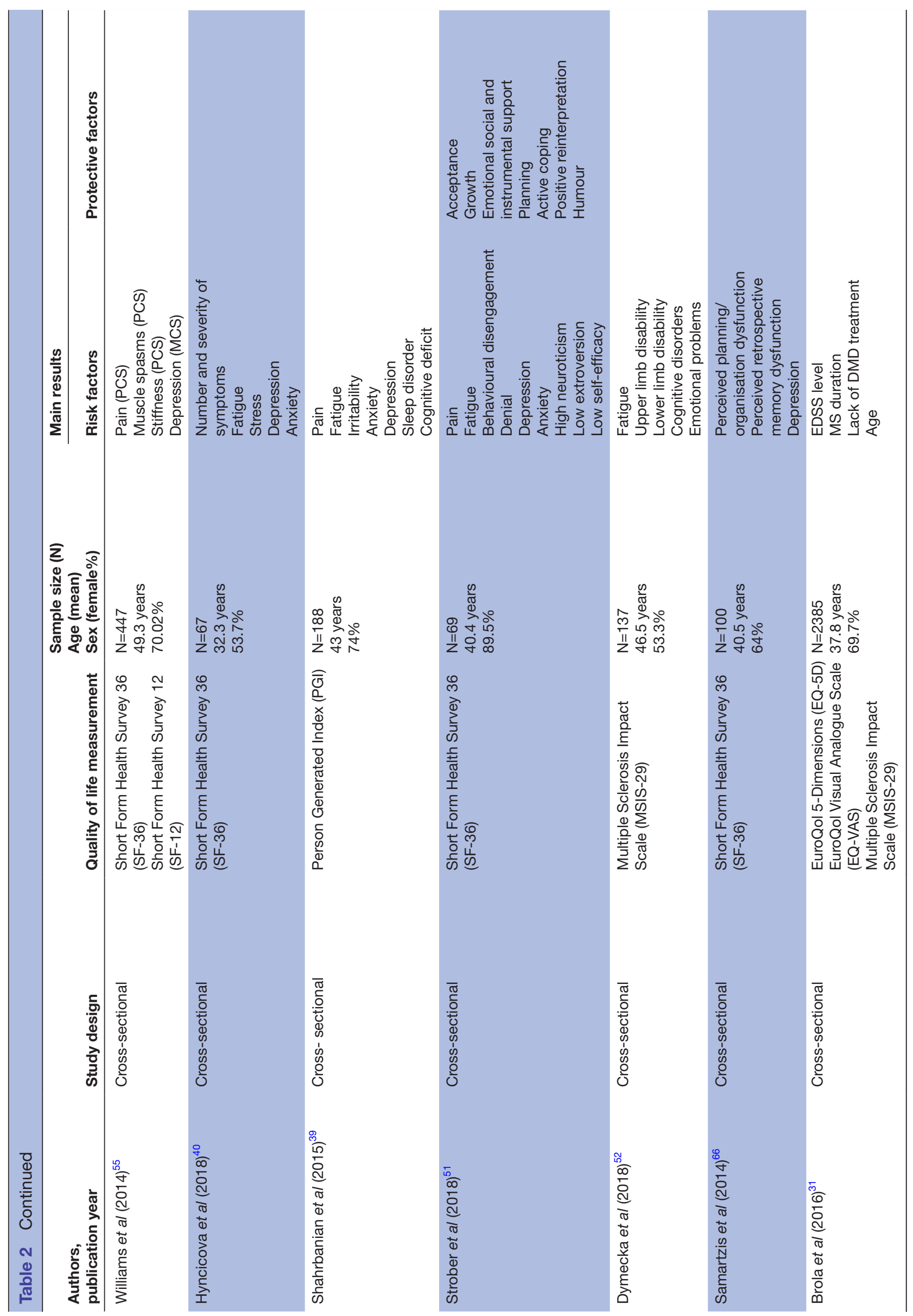




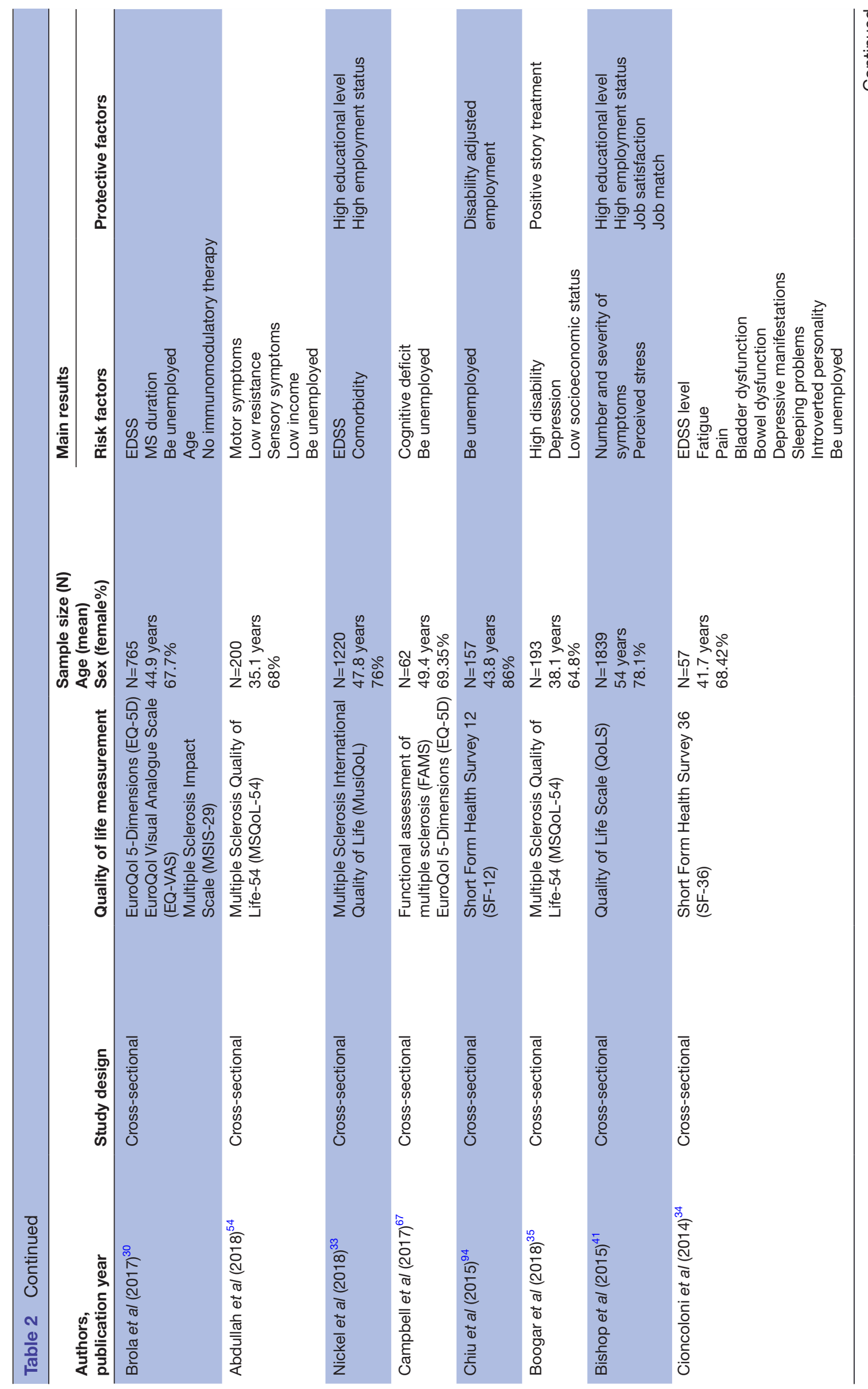




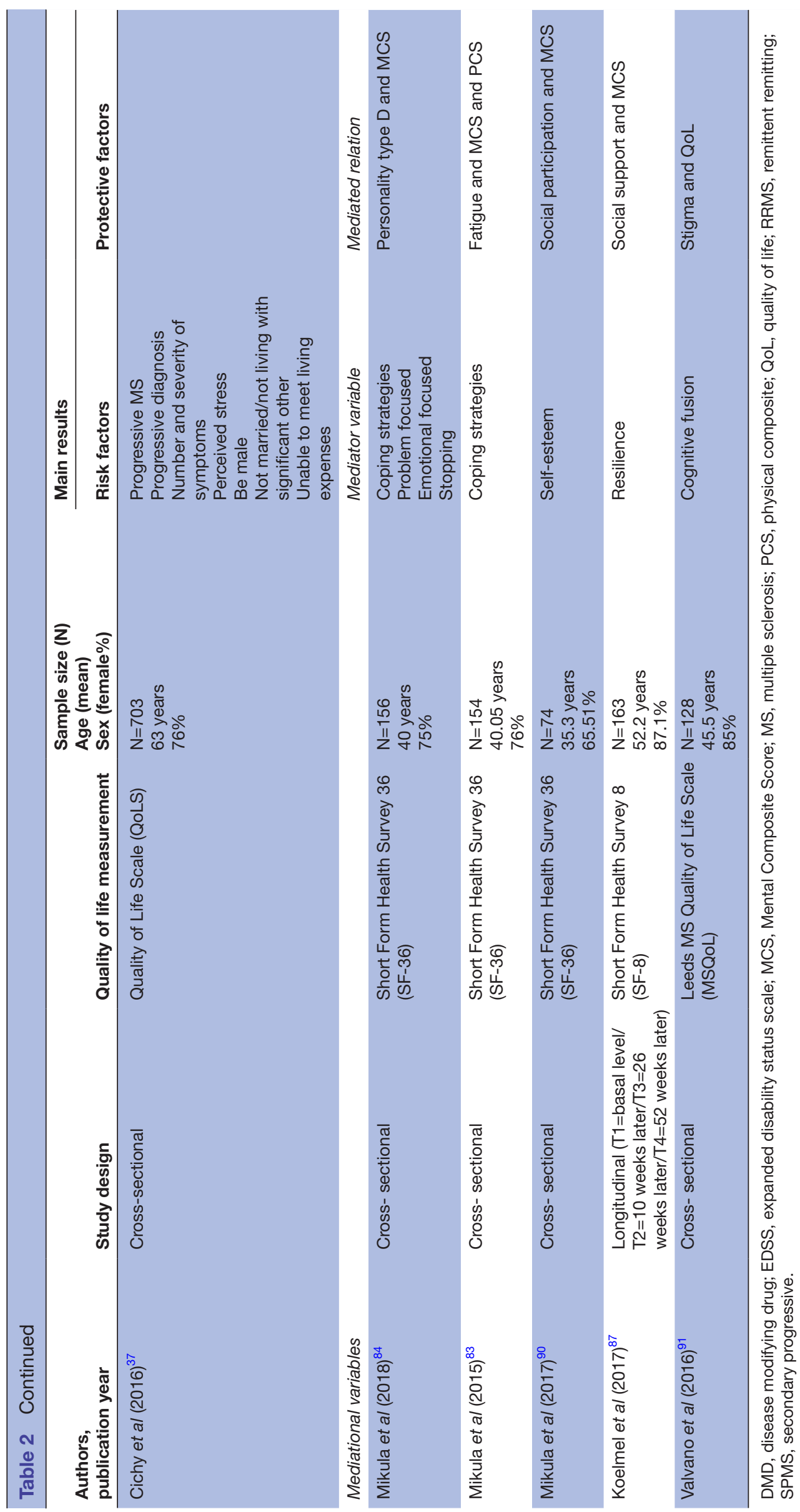

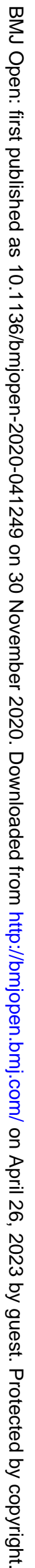




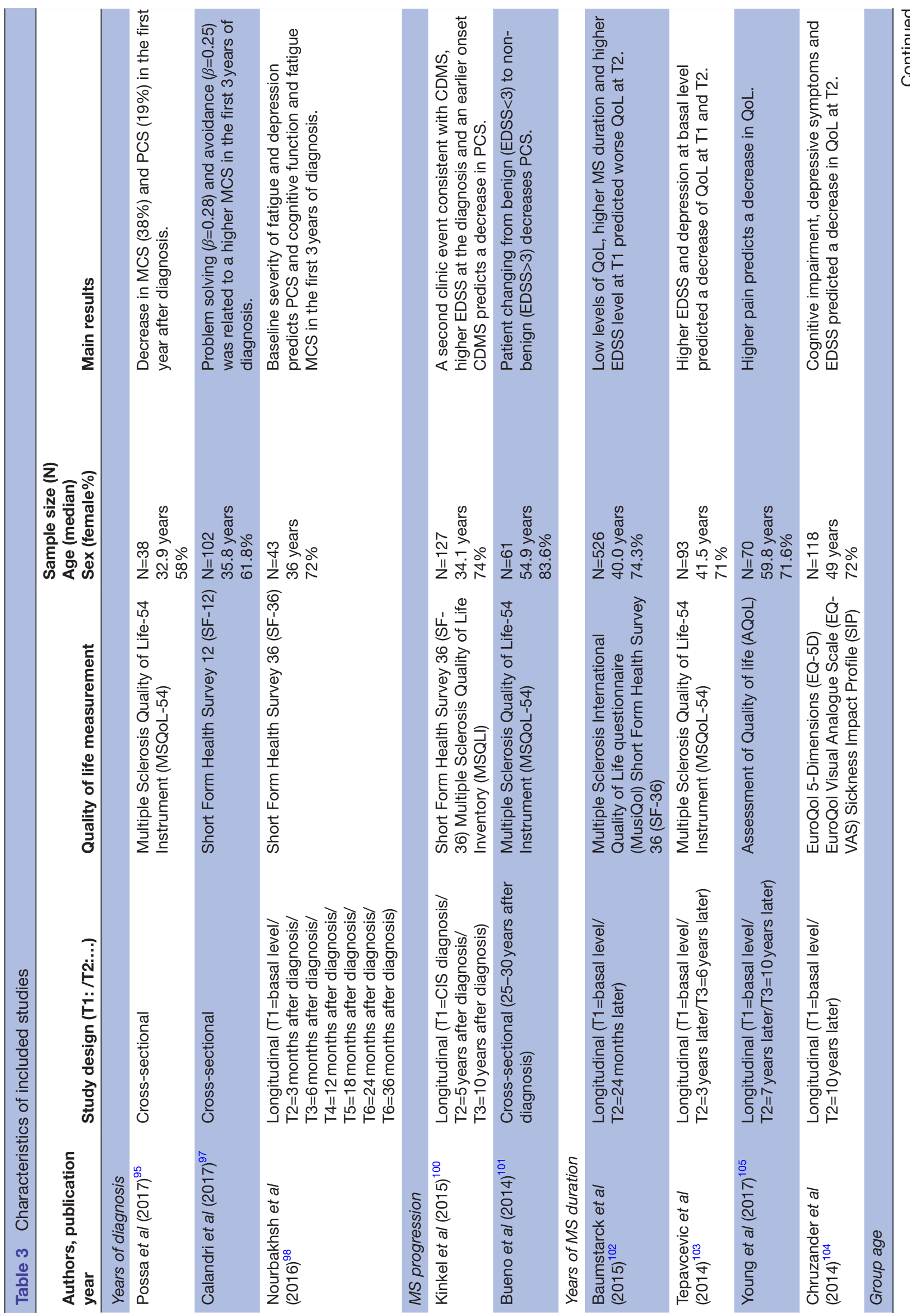


displayed an association between unemployment and lower QoL. ${ }^{30} 34546794$ Others showed a positive correlation between jobs adapted to disability, ${ }^{94}$ job match and job satisfaction, ${ }^{41}$ high employment status ${ }^{33}$ and QoL in MS. Low socioeconomic status ${ }^{35}$ and financial straits ${ }^{37}$ were also risk factors for lower QoL.

Brola et $a l^{3031}$ noted that not having access to an adequate pharmacological treatment put QoL in danger. Congruent with this finding, Boogar et $a l^{35}$ found a positive treatment experience to be a protective factor.

Other sociodemographic variables related to poorer QoL in MS were male sex, ${ }^{37}$ old age ${ }^{30}{ }^{31}$ unmarried or living with significant others, ${ }^{37}$ whereas a higher education was a protective factor. ${ }^{33}$

\section{Disease history}

Some of the selected studies examined QoL in MS in its early years. According to Possa et al, ${ }^{95}$ QoL decreased in the first year of diagnosis, as assessed by the MCS and Physical Composite Score (PCS). Stern et a ${ }^{96}$ found the worst QoL in the youngest group of patients with MS .

Calandri $e t a l^{97}$ found that during the first 3 years from diagnosis, problem solving and avoidance coping strategies had a positive effect on QoL. Nourbakhsh $e t$ a $\ell^{8}$ also studied factors influencing the development of QoL in the first 3 years. Their results showed that higher baseline levels of fatigue and depression predicted worse QoL as assessed by the PCS, whereas lower cognitive functioning and higher fatigue predicted a worse MCS.

Another study on QoL in MS by Buhse et a $t^{99}$ focused on old age. These authors identified neurological impairment, physical disability, depression and comorbidity with thyroid disease as risk factors for worse QoL as assessed by the PCS in a sample of elderly patients with MS. On the contrary, being widowed and employed were identified as protective PCS factors.

In a longitudinal study, Kinkel et $a l^{100}$ showed that a second clinical event consistent with clinically defined MS, higher EDSS at the time of diagnosis and an earlier MS onset predicted a decrease in PCS 10 years after diagnosis. Bueno $e t a l^{101}$ also showed that progression from benign MS to non-benign MS predicted a decrease in PCS 25-30 years after diagnosis.

Some longitudinal predictors of QoL identified have been: longer MS duration predicted worse QoL 2 years later, ${ }^{102}$ and worse EDSS predicted worse QoL $2,{ }^{102} 6,{ }^{103}$ and $10^{104}$ years later. Depression predicted worse QoL $6^{103}$ and $10^{104}$ years later, and stronger pain ${ }^{105}$ and cognitive impairment ${ }^{104}$ predicted worse QoL 10 years later.

\section{Interventions}

Details of the selected articles on psychological intervention are presented in table 4 .

\section{Mindfulness-based therapies}

All mindfulness-based therapy intervention programmes showed improvement in QoL at some evaluation point and at least in some QoL domains. Body-affective 


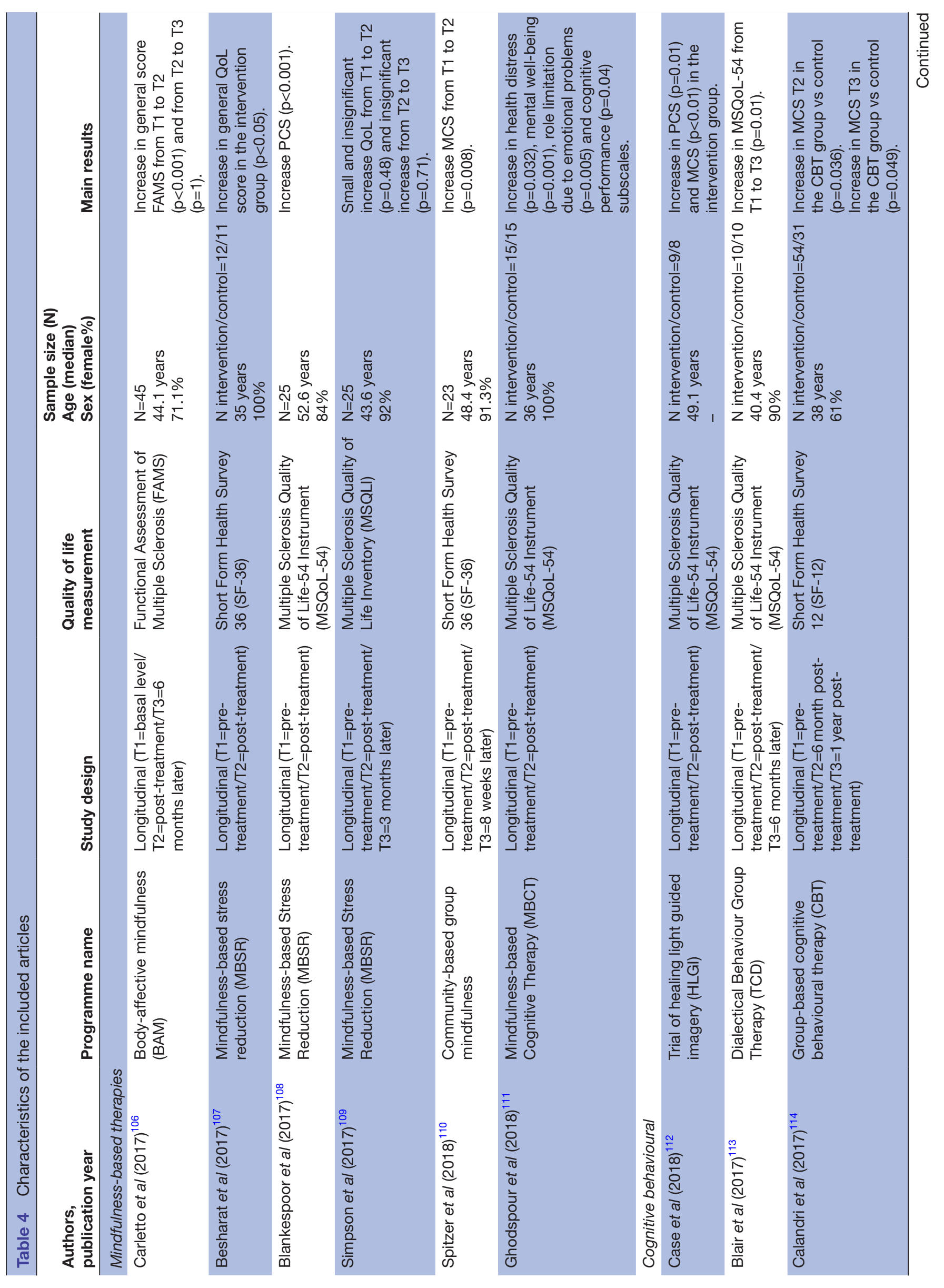




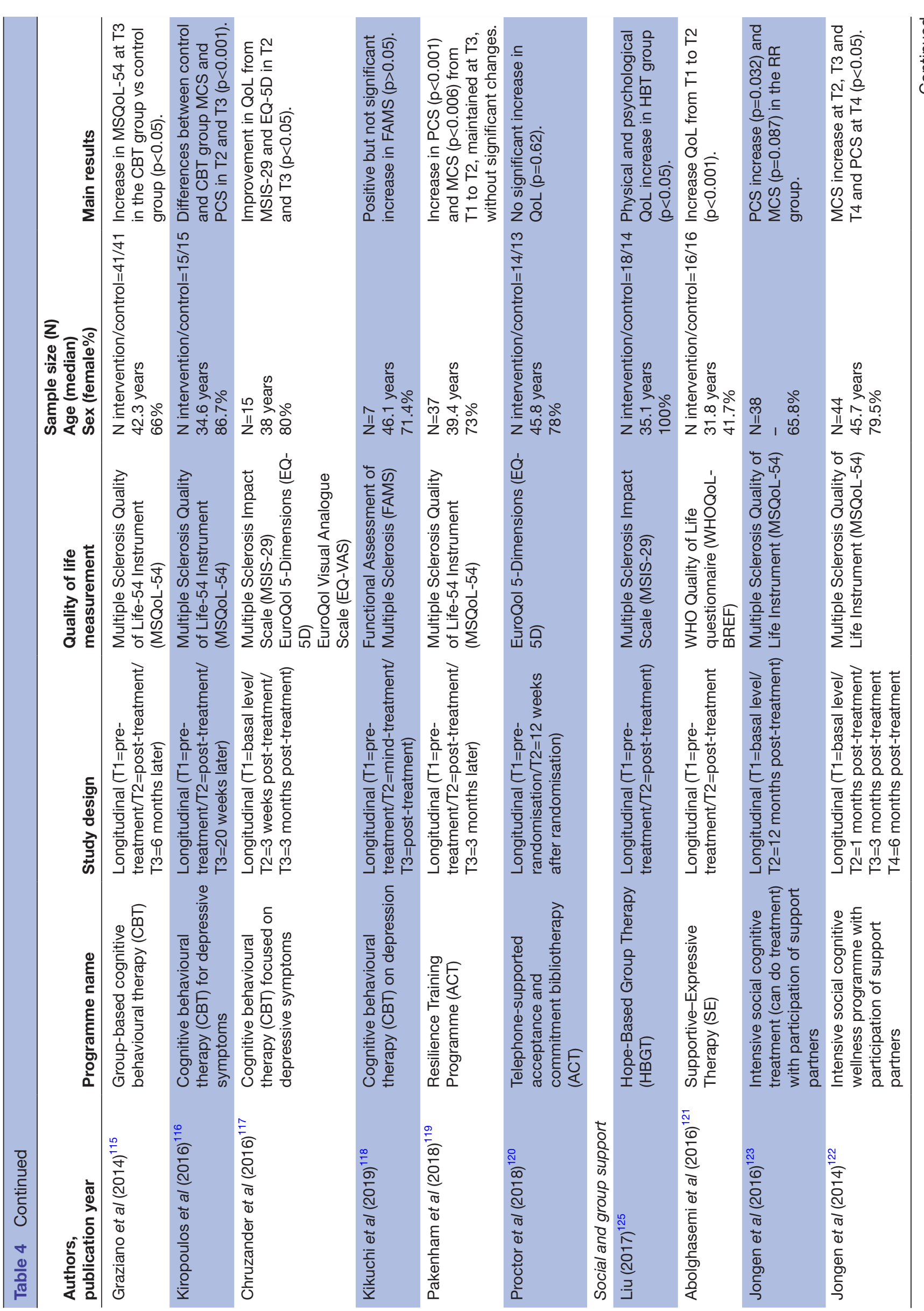




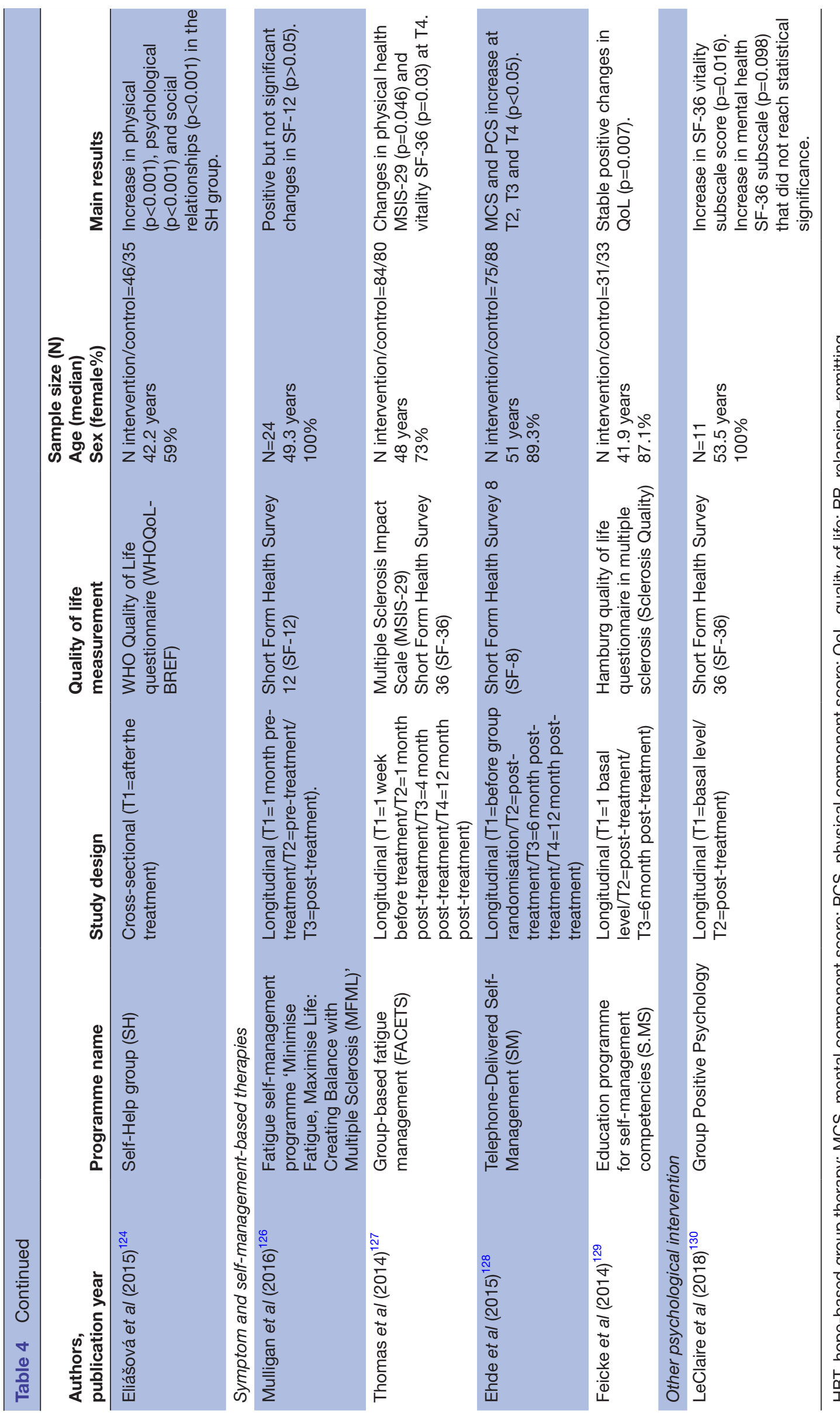

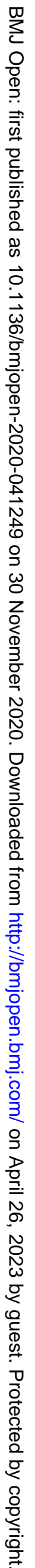


mindfulness intervention increased the general QoL score up to 6 months after treatment. ${ }^{106}$

Of the three studies on mindfulness-based stress reduction programmes, two showed a significant increase in QoL after treatment. ${ }^{107-109}$ One study ${ }^{109}$ only produced a small, insignificant increase after treatment and at the 3-month follow-up.

A community-based mindfulness programme resulted in a significant increase in MCS. ${ }^{110}$

Finally, mindfulness-based cognitive therapy did not show any significant difference in general QoL between the control and the experimental group; however, it did show significant differences in QoL: in health distress, mental well-being, role limitation due to emotional problems and cognitive performance. ${ }^{111}$

\section{Cognitive behavioural}

A wide spectrum of cognitive behavioural interventions was analysed.

In a study by Case $e t a l,{ }^{112}$ the experimental group attended 10 1-hour weekly sessions of healing light guided imagery. They found a greater increase in QoL in this group than with 10 hours of positive journaling in the active control group.

Blair $e t a l^{133}$ focused intervention on emotion regulation. The design consisted of 16 1.5-hour biweekly sessions for 8 weeks. The intervention resulted in a significant increase in QoL 6 months after treatment.

Interventions by Calandri et $a l^{114}$ and Graziano et $a l^{15}$ had a comparable design. Participants were divided into two subgroups by age. Intervention comprised four to five 2-hour sessions over the course of 2 months, and one follow-up session 6 months after treatment. Calandri et $a l^{114}$ also included one follow-up session 12 months after treatment. At follow-up, the intervention groups in both studies had experienced an increase in QoL.

Three studies ${ }^{116-118}$ focused intervention on depressive symptoms. Kiropoulos et $a l^{16}$ and Chruzander et $a l^{17}$ found improvement in QoL at post-treatment and follow-up assessments. Kikuchi et $a l^{188}$ also found a posttreatment improvement, but not significant.

Two of the studies based intervention on acceptance and commitment therapy (ACT). Pakenham et al ${ }^{119}$ implemented an 8-week programme aimed at training in resilience. QoL increased at treatment end and at 3-month follow-up. Proctor et $a l^{20}$ implemented an 8-week intervention comprising telephone calls and self-help ACT books. No significant increase in QoL was observed.

\section{Social and group support}

The following social support and group interventions had an impact on QoL in MS.

Abolghasemi et al $^{121}$ implemented a 12-session supportive-expressive therapy programme, which improved QoL.

Jongen $e t a l^{122}$ tested an intensive social-cognitive wellness programme involving the partner or other significant informal caregiver. The results showed an increase in the MCS at 1, 3 and 6 months from treatment and in the PCS
6 months after treatment. The results of the programme were evaluated again 12 months after treatment. The relapsing-remitting MS group showed an increase in PCS and MCS. ${ }^{123}$

Eliášová et $a l^{124}$ found more improvement across several QoL domains in patients with MS after self-help group sessions than in patients who did not attend the selfhelp groups. Liu ${ }^{125}$ detected an increase in physical and psychological QoL in women with MS after participating in a hope-based group therapy programme for 1 hour twice a week for 8 weeks.

\section{Symptom and self-management-based therapies}

Two studies analysed a fatigue self-management group therapy. Mulligan $e t a l^{126}$ reported positive, but not significant, changes in QoL after their treatment. Thomas et $a l^{127}$ reported significant positive changes in physical health assessed by the Multiple Sclerosis Impact Scale (MSIS-29) and vitality as measured by the SF-36 in the intervention group 12 months after the treatment.

In addition to fatigue self-management, Ehde et al ${ }^{128}$ focused in their intervention on pain and depression self-management. The results were compared with an educational programme. There was a higher QoL post-treatment and 12-month follow-up score in the self-management group. Feicke $e t$ al ${ }^{129}$ implemented a programme focused on MS self-management. As in Ehde et al, ${ }^{128}$ improvements in QoL were still maintained at 6-month follow-up.

\section{Other psychological intervention}

LeClaire $e a^{130}$ implemented a 5-week positive psychology programme. The results showed only a significant improvement in the SF-36 vitality subscale.

\section{DISCUSSION}

First, the present systematic review was intended to identify risk and QoL protective factors in MS. The results showed that the EDSS was most employed for assessment of functional impairment. ${ }^{25-35}$ As expected, the number and severity of symptoms and associated impairment appeared to play a crucial role in QoL. Fatigue, $2829394042-52$ cognitive impairment, ${ }^{39} 505253636667$ and pain,, 35950515556 in particular, were the focus of a large number of studies and were confirmed as important risk factors. Longitudinal studies suggested that greater fatigue, ${ }^{98}$ pain ${ }^{105}$ and cognitive impairment ${ }^{98} 104$ also predicted worse QoL up to 10 years later. This has important clinical implications, as treatment of the abovementioned symptoms should be prioritised. In general, functional impairment, ${ }^{102-104}$ as well as longer duration of illness, ${ }^{102}$ was predictor of QoL 2 to 10 years later, whereas disease progression ${ }^{101}$ from benign to non-benign MS predicted QoL as measured by the PCS up to 30 years later.

Among the emotional symptoms, there was convincing evidence that depression, ${ }^{28} 2932343539405155666971-75$ along with depressive temperament ${ }^{77}$ and anxiety, $3840516971-7476$ 
were associated with lower QoL and that depression also predicted QoL up to 10 years later. ${ }^{104}$

The coping strategies applied obviously influenced QoL in MS, however their effect depended on the specific circumstances of the disease history. For example, problem solving and avoidance coping, normally classified as opposite strategies, both seemed to have a positive effect on the MCS in the first 3 years of diagnosis. ${ }^{97}$ However, in general, strategies associated with denial ${ }^{5179}$ and avoidance of the challenges of the disease, such as problem avoidance, ${ }^{71} 81$ behavioural disengagement, ${ }^{51}{ }^{80}$ distancing, ${ }^{81}$ self-distraction, ${ }^{79}$ social withdrawal ${ }^{71}$ and wishful thinking, ${ }^{71}$ were associated with a lower QoL. On the contrary, strategies based on acceptance and active commitment, such as active coping, humour, problem resolution, cognitive positive restructuring and emotional expression, led to higher QoL in MS. ${ }^{51} 71$ 79-82 Obviously, there is a close connection between the active confrontation of the challenges of illness and specific personality-based convictions, such as a high self-efficacy. Thus, higher self-efficacy, ${ }^{5188}$ self-esteem ${ }^{88}$ and sense of coherence ${ }^{89}$ improved QoL in MS.

Regarding sociodemographic influences on QoL, not surprisingly, unemployment, a low socioeconomic status $^{35}$ and financial difficulties ${ }^{37}$ proved to be major risk factors. ${ }^{30} 34546794$ In keeping with the negative influence of the scarcity of resources, lack of access to therapy was also identified as a risk factor. ${ }^{30} 31$

The second aim of this systematic review was to study QoL in patients with MS at different times during their disease history. Two studies showed diminishing QoL in patients with MS in its early stage..$^{96}$ This might have to do with the fact that patients being diagnosed with a severe chronic disease need a certain time to come to terms with this emotional shock. Oscillation between avoidance and problem solving, which both have a positive influence in the first 3years after diagnosis, ${ }^{97}$ may be behind this inner struggle. In older patients, neurological impairment and physical disability, ${ }^{97}$ which represent the age-associated increase in physical impairment, were identified as risk factors for QoL in MS.

Finally, the third aim of this review was to analyse psychological interventions for the improvement of QoL in MS. Symptomatic improvement of psychopathology usually at the centre of psychotherapy outcome studies was not the primary focus of our review. ${ }^{131}$ Eight of the intervention studies specifically treated depressive symptomatology, ${ }^{106}$ 110-112 115117118 either with mindfulness-based or cognitive behavioural approaches, both of which proved to be successful.

Three studies were specifically directed towards the treatment of fatigue ${ }^{112} 126127$ by light guided imagery or self-management programmes. Both the imagery and selfmanagement group intervention approaches were successful, whereas the individual self-management programme did not show significant improvement.

A variety of mindfulness-based approaches ${ }^{107-109}$ and a community-based intervention were directed at stress reduction. ${ }^{110}$ Three of the four studies showed some kind of improvement in QoL, including the only study with a control group.

Several of the interventions were designed to reinforce protective factors in patients with MS. Graziano et $a l^{15}$ focused on identity redefinition, sense of coherence and selfefficacy. Pakenham et al ${ }^{19}$ implemented a programme based on resilience training, and the programme by Blair et $a l^{113}$ focused on the improvement of emotional regulation. All of them were successful in improving QoL, confirming the alternative focus on protective factors instead of risk factors.

A wide spectrum of interventions based on social support concentrated on reinforcement of the social network of patients with MS, for example, self-help groups, ${ }^{124}$ hope-based group therapy, ${ }^{125}$ supportive-expressive therapy ${ }^{121}$ and social cognitive training with support partners. ${ }^{122} 123$ All interventions aimed at helping people overcome MS barriers in daily living by strengthening their social support, improving some aspects of QoL. This is consistent with the studies mentioned above $^{9293}$ and emphasises the importance of social support and participation as a protective factor for QoL.

\section{Limitations}

The main limitation of this study was the impossibility of carrying out a quantitative synthesis of the results, due to the heterogeneity of methodologies and designs in the articles included. Due to the vast number of topics and limited resources, our search was restricted to a 5 -year period through January 2019.

\section{CONCLUSIONS}

This review was intended to give a broad overview of QoL in MS. The findings show the importance of clinical, psychosocial and demographic variables as QoL risk and protective factors. A variety of psychological interventions ranging from mindfulness-based and cognitive behavioural approaches to self-help groups addressing these factors were identified as promising options for improving QoL. These findings have important clinical implications. A sound biopsychosocial assessment of patients with MS in daily clinical practice is necessary to ensure the possibility of early identification of QoL risk factors and evidence-based psychological intervention is recommended to improve or stabilise QoL.

Contributors IG-G, AM-R, RC and MÁP-S-G contributed to conceptualisation, investigation, methodology, validation, writing original draft and writing review and editing.

Funding This study was financially supported by the program of Formation of University Professor of Ministry of Education, Culture and Sport of Spain grant number: FPU 17/04240.

Competing interests None declared.

Patient consent for publication Not required.

Ethics approval Not required.

Provenance and peer review Not commissioned; externally peer reviewed.

Data availability statement No data are available. All data relevant to the study are included in the article or uploaded as supplemental information.

Supplemental material This content has been supplied by the author(s). It has not been vetted by BMJ Publishing Group Limited (BMJ) and may not have been peer-reviewed. Any opinions or recommendations discussed are solely those 
of the author(s) and are not endorsed by BMJ. BMJ disclaims all liability and responsibility arising from any reliance placed on the content. Where the content includes any translated material, BMJ does not warrant the accuracy and reliability of the translations (including but not limited to local regulations, clinical guidelines, terminology, drug names and drug dosages), and is not responsible for any error and/or omissions arising from translation and adaptation or otherwise.

Open access This is an open access article distributed in accordance with the Creative Commons Attribution Non Commercial (CC BY-NC 4.0) license, which permits others to distribute, remix, adapt, build upon this work non-commercially, and license their derivative works on different terms, provided the original work is properly cited, appropriate credit is given, any changes made indicated, and the use is non-commercial. See: http://creativecommons.org/licenses/by-nc/4.0/.

\section{ORCID iD}

Irene Gil-González http://orcid.org/0000-0002-1810-3687

\section{REFERENCES}

1 World Health Organisation. Governance. Basic documents. World health organisation, 2019. Available: https://www.who.int/about/ who-we-are/constitution [Accessed 15 Dec 2019].

2 Patti F, Pappalardo A. Quality of life in patients affected by multiple sclerosis: a systematic review. In: Preedy VR, Watson RR, eds. Handbook of disease burdens and quality of life measures. New York (NY: New York: Springer, 2010: 3769-83.

3 Bernstein U. The world Health organization quality of life assessment (WHOQOL) position paper from the world Helath organization. SocSciMed 1995;41:1403-9.

4 Post MWM, Marcel WM. Definitions of quality of life: what has happened and how to move on. Top Spinal Cord Inj Rehabil 2014;20:167-80.

5 Gellert GA. The importance of quality of life research for health care reform in the USA and the future of public health. Qual Life Res 1993;2:357-61.

6 Benito-León J, Morales JM, Rivera-Navarro J, et al. A review about the impact of multiple sclerosis on health-related quality of life. Disabil Rehabil 2003;25:1291-303.

7 Hyarat SY, Subih M, Rayan A, et al. Health related quality of life among patients with multiple sclerosis: the role of psychosocial adjustment to illness. Arch Psychiatr Nurs 2019;33:11-16.

8 Yalachkov Y, Soydaș D, Bergmann J, et al. Determinants of quality of life in relapsing-remitting and progressive multiple sclerosis. Mult Scler Relat Disord 2019;30:33-7.

9 Amtmann D, Bamer AM, Kim J, et al. People with multiple sclerosis report significantly worse symptoms and health related quality of life than the US general population as measured by PROMIS and NeuroQoL outcome measures. Disabil Health J 2018;11:99-107.

10 Pittock SJ, Mayr WT, McClelland RL, et al. Quality of life is favorable for most patients with multiple sclerosis: a population-based cohort study. Arch Neurol 2004;61:679-86.

11 McCabe MP, McKern S. Quality of life and multiple sclerosis: comparison between people with multiple sclerosis and people from the general population. $J$ Clin Psychol Med Settings 2002;9:287-95.

12 Schmidt S, Vilagut G, Garin O, et al. [Reference guidelines for the 12-Item Short-Form Health Survey version 2 based on the Catalan general population]. Med Clin 2012;139:613-25.

13 Petrović N, Prlić N, Gašparić I, et al. Quality of life among persons suffering from multiple sclerosis. Medica Jadertina 2019;49:217-26 https://hrcak.srce.hr/234930

14 Algahtani HA, Shirah BH, Alzahrani FA, et al. Quality of life among multiple sclerosis patients in Saudi Arabia. Neurosci 2017;22:261-6.

15 Wilski M, Gabryelski J, Brola W, et al. Health-Related quality of life in multiple sclerosis: links to acceptance, coping strategies and disease severity. Disabil Health J 2019;12:608-14.

16 Pérez de Heredia-Torres M, Huertas-Hoyas E, Sánchez-Camarero $\mathrm{C}$, et al. Occupational performance in multiple sclerosis and its relationship with quality of life and fatigue. Eur J Phys Rehabil Med 2020;56:148-54.

17 Ochoa-Morales A, Hernández-Mojica T, Paz-Rodríguez F, et al. Quality of life in patients with multiple sclerosis and its association with depressive symptoms and physical disability. Mult Scler Relat Disord 2019;36:101386.

18 Dorstyn DS, Roberts RM, Murphy G, et al. Employment and multiple sclerosis: a meta-analytic review of psychological correlates. $J$ Health Psychol 2019;24:38-51.
19 Schmidt S, Jöstingmeyer P, Depression JP. Depression, fatigue and disability are independently associated with quality of life in patients with multiple sclerosis: results of a cross-sectional study. Mult Scler Relat Disord 2019;35:262-9.

20 Ysrraelit MC, Fiol MP, Gaitán MI, et al. Quality of life assessment in multiple sclerosis: different perception between patients and neurologists. Front Neurol 2018;8:1-6.

21 Revicki DA, Osoba D, Fairclough D, et al. Recommendations on health-related quality of life research to support labeling and promotional claims in the United States. Qual Life Res 2000;9:887-900.

22 Baumstarck K, Boyer L, Boucekine M, et al. Measuring the quality of life in patients with multiple sclerosis in clinical practice: a necessary challenge. Mult Scler Int 2013;2013:1-8.

23 Moher D, Shamseer L, Clarke M, et al. Preferred reporting items for systematic review and meta-analysis protocols (PRISMA-P) 2015 statement. Syst Rev 2015;4:1.

24 Chacón-Moscoso S, Sanduvete-Chaves S, Sánchez-Martín M. The development of a checklist to enhance methodological quality in intervention programs. Front Psychol 2016;7:1811.

25 Gupta S, Goren A, Phillips AL, et al. Self-Reported severity among patients with multiple sclerosis in the U.S. and its association with health outcomes.. Mult Scler Relat Disord 2014;3:78-88.

26 Rezapour A, Almasian Kia A, Goodarzi S, et al. The impact of disease characteristics on multiple sclerosis patients' quality of life. Epidemiol Health 2017;39:e2017008-7.

27 Nakazawa K, Noda T, Ichikura K, et al. Resilience and depression/ anxiety symptoms in multiple sclerosis and neuromyelitis optica spectrum disorder. Mult Scler Relat Disord 2018;25:309-15.

28 Ciampi E, Uribe-San-Martin R, Vásquez M, et al. Relationship between social cognition and traditional cognitive impairment in progressive multiple sclerosis and possible implicated neuroanatomical regions. Mult Scler Relat Disord 2018:20:122-8.

29 Klevan G, Jacobsen CO, Aarseth JH, et al. Health related quality of life in patients recently diagnosed with multiple sclerosis. Acta Neurol Scand 2014;129:21-6.

30 Brola W, Sobolewski P, Jantarski K. Multiple sclerosis: patientreported quality of life in the Świętokrzyskie region. Med Stud Med 2017:33:191-8.

31 Brola W, Sobolewski P, Fudala M, et al. Self-Reported quality of life in multiple sclerosis patients: preliminary results based on the Polish MS registry. Patient Prefer Adherence 2016;10:1647-56.

32 Fernández-Jiménez E, Arnett PA. Impact of neurological impairment, depression, cognitive function and coping on quality of life of people with multiple sclerosis: a relative importance analysis. Mult Scler 2015;21:1468-72.

33 Nickel S, von dem Knesebeck O, Kofahl C. Self-assessments and determinants of HRQoL in a German MS population. Acta Neurol Scand 2018:137:174-80.

34 Cioncoloni D, Innocenti I, Bartalini S, et al. Individual factors enhance poor health-related quality of life outcome in multiple sclerosis patients. significance of predictive determinants. J Neurol Sci 2014;345:213-9.

35 Boogar IR, Talepasand S, Jabari M. Psychosocial and medical determinants of health-related quality of life in patients with relapsing-remitting multiple sclerosis. Noro Psikiyatr Ars 2018;55:29-35.

36 Gross HJ, Watson C, Characteristics WC. Burden of illness, and physical functioning of patients with relapsing-remitting and secondary progressive multiple sclerosis: a cross-sectional us survey. Neuropsychiatr Dis Treat 2017;13:1349-57.

37 Cichy KE, Li J, Rumrill PD, et al. Non-vocational health-related correlates of quality of life for older adults living with multiple sclerosis. J Rehabil 2016;82:36-44.

38 Zhang Y, Taylor BV, Simpson S, et al. Patient-reported outcomes are worse for progressive-onset multiple sclerosis than relapse-onset multiple sclerosis, particularly early in the disease process. Eur $J$ Neurol 2019;26:155-61.

39 Shahrbanian S, Duquette P, Kuspinar A, et al. Contribution of symptom clusters to multiple sclerosis consequences. Qual Life Res 2015;24:617-29.

40 Hyncicova E, Kalina A, Vyhnalek M, et al. Health-Related quality of life, neuropsychiatric symptoms and structural brain changes in clinically isolated syndrome. PLoS One 2018;13:e0200254-13.

41 Bishop M, Rumrill PD, Roessler RT. Quality of life among people with multiple sclerosis: replication of a three-factor prediction model. Work 2015:52:757-65.

42 Leonavicius R. Among multiple sclerosis and fatigue. Neurology, Psychiatry and Brain Research 2016;22:141-5.

43 Garg H, Bush S, Gappmaier E. Associations between fatigue and disability, functional mobility, depression, and quality of life in people with multiple sclerosis. Int J MS Care 2016;18:71-7. 
44 Fernández-Muñoz JJ, Morón-Verdasco A, Cigarán-Méndez M, et al Disability, quality of life, personality, cognitive and psychological variables associated with fatigue in patients with multiple sclerosis. Acta Neurol Scand 2015;132:118-24.

45 Weiland TJ, Jelinek GA, Marck CH, et al. Clinically significant fatigue: prevalence and associated factors in an international sample of adults with multiple sclerosis recruited via the Internet. PLoS One 2015;10:e0115541-18.

46 Aygunoglu SK, Çelebİ A, Vardar N, et al. Correlation of fatigue with depression, disability level and quality of life in patients with multiple sclerosis. Arch Neuropsychiatr 2015;52:247-51.

47 Vister E, Tijsma ME, Hoang PD, et al. Fatigue, physical activity, quality of life, and fall risk in people with multiple sclerosis. Int J MS Care 2017;19:91-8.

48 Tabrizi FM, Radfar M, Fatigue RM. Fatigue, sleep quality, and disability in relation to quality of life in multiple sclerosis. Int J MS Care 2015;17:268-74.

49 Barin L, Salmen A, Disanto G, et al. The disease burden of multiple sclerosis from the individual and population perspective: which symptoms matter most? Mult Scler Relat Disord 2018;25:112-21.

50 Kratz AL, Ehde DM, Hanley MA, et al. Cross-Sectional examination of the associations between symptoms, community integration, and mental health in multiple sclerosis. Arch Phys Med Rehabil 2016;97:386-94.

51 Strober LB. Quality of life and psychological well-being in the early stages of multiple sclerosis (MS): importance of adopting a biopsychosocial model. Disabil Health J 2018;11:555-61.

52 Dymecka J, Bidzan M. Biomedical variables and adaptation to disease and health-related quality of life in Polish patients with MS. Int J Environ Res Public Health 2018;15:2678.

53 Colbeck M, processing S. Sensory processing, cognitive fatigue, and quality of life in multiple sclerosis. Can J Occup Ther 2018;85:169-75.

54 Abdullah EJ, Badr HE. Assessing the quality of life in patients with multiple sclerosis in Kuwait: a cross sectional study. Psychol Health Med 2018;23:391-9.

55 Williams AE, Vietri JT, Isherwood G, et al. Symptoms and association with health outcomes in relapsing-remitting multiple sclerosis: results of a US patient survey. Mult Scler Int 2014;2014:1-8.

56 Marck CH, De Livera AM, Weiland TJ, et al. Pain in people with multiple sclerosis: associations with modifiable lifestyle factors, fatigue, depression, anxiety, and mental health quality of life. Front Neurol 2017;8:1-7.

57 Milinis K, Tennant A, Young CA. Spasticity in multiple sclerosis: associations with impairments and overall quality of life. Mult Scler Relat Disord 2016;5:34-9.

58 Zettl UK, Henze T, Essner U, et al. Burden of disease in multiple sclerosis patients with spasticity in Germany: mobility improvement study (move I). Eur J Health Econ 2014;15:953-66.

59 Khalaf KM, Coyne KS, Globe DR, et al. The impact of lower urinary tract symptoms on health-related quality of life among patients with multiple sclerosis. Neurourol Urodyn 2016;35:48-54.

60 Vitkova M, Rosenberger J, Krokavcova M, et al. Health-Related quality of life in multiple sclerosis patients with bladder, bowel and sexual dysfunction. Disabil Rehabil 2014;36:987-92.

61 Qaderi K, Merghati Khoei E. Sexual problems and quality of life in women with multiple sclerosis. Sex Disabil 2014;32:35-43.

62 Schairer LC, Foley FW, Zemon V, et al. The impact of sexual dysfunction on health-related quality of life in people with multiple sclerosis. Mult Scler 2014;20:610-6.

63 Ma S, Rui X, Qi P, et al. Sleep disorders in patients with multiple sclerosis in China. Sleep Breath 2017;21:149-54.

64 White EK, Sullivan AB, Drerup M. Short report: impact of sleep disorders on depression and Patient-Perceived health-related quality of life in multiple sclerosis. Int J MS Care 2019;21:10-14.

65 Grech LB, Kiropoulos LA, Kirby KM, et al. The effect of executive function on stress, depression, anxiety, and quality of life in multiple sclerosis. J Clin Exp Neuropsychol 2015;37:549-62.

66 Samartzis L, Gavala E, Zoukos Y, et al. Perceived cognitive decline in multiple sclerosis impacts quality of life independently of depression. Rehabil Res Pract 2014;2014:1-6.

67 Campbell J, Rashid W, Cercignani M, et al. Cognitive impairment among patients with multiple sclerosis: associations with employment and quality of life. Postgrad Med J 2017;93:143-7.

68 Sgaramella TM, Carrieri L, Stenta G, et al. Self-Reported executive functioning and satisfaction for quality of life dimensions in adults with multiple sclerosis. Int J Child Heal Hum Dev 2014;7:167.

69 Paziuc LC, Radu MR. The influence of mixed anxiety-depressive disorder on the perceived quality of life in multiple sclerosis patients. Bulletin of the Transilvania University of Brasov, Seriels VI: Medical Sciences 2018;11:41-50.
70 Phillips LH, Henry JD, Nouzova E, et al. Difficulties with emotion regulation in multiple sclerosis: links to executive function, mood, and quality of life. J Clin Exp Neuropsychol 2014;36:831-42.

71 Hernández-Ledesma AL, Rodríguez-Méndez AJ, Gallardo-Vidal LS, et al. Coping strategies and quality of life in Mexican multiple sclerosis patients: physical, psychological and social factors relationship. Mult Scler Relat Disord 2018;25:122-7.

72 Prisnie JC, Sajobi TT, Wang M, et al. Effects of depression and anxiety on quality of life in five common neurological disorders. Gen Hosp Psychiatry 2018;52:58-63.

73 Alsaadi T, Hammasi KE, Shahrour TM, et al. Depression and anxiety as determinants of health-related quality of life in patients with multiple sclerosis - United Arab Emirates. Neurol Int 2017;9:75-8.

74 Labiano-Fontcuberta A, Mitchell AJ, Moreno-García S, et al. Impact of anger on the health-related quality of life of multiple sclerosis patients. Mult Scler 2015;21:630-41.

75 Fernández-Muñoz JJ, Cigarán-Méndez M, Navarro-Pardo E, et al. Is the association between health-related quality of life and fatigue mediated by depression in patients with multiple sclerosis? A Spanish cross-sectional study. BMJ Open 2018;8:e016297-6.

76 Pham T, Jetté N, Bulloch AGM, et al. The prevalence of anxiety and associated factors in persons with multiple sclerosis. Mult Scler Relat Disord 2018;19:35-9.

77 Salhofer-Polanyi S, Friedrich F, Löffler S, et al. Health-Related quality of life in multiple sclerosis: temperament outweighs EDSS. BMC Psychiatry 2018;18:1-6.

78 Demirci S, Demirci K, Demirci S. The effect of type D personality on quality of life in patients with multiple sclerosis. Arch Neuropsychiatr 2017;54:272-6.

79 Zengin O, Erbay E, Yıldırım B, et al. Quality of life, coping, and social support in patients with multiple sclerosis: a pilot study. Tnd 2017;23:211-8 https://doi.org/

80 Grech LB, Kiropoulos LA, Kirby KM, et al. Target coping strategies for interventions aimed at maximizing psychosocial adjustment in people with multiple sclerosis. Int J MS Care 2018;20:109-19.

81 Farran N, Ammar D, Darwish H. Quality of life and coping strategies in Lebanese multiple sclerosis patients: a pilot study. Mult Scler Relat Disord 2016;6:21-7.

82 Mikula P, Nagyova I, Krokavcova M, et al. Coping and its importance for quality of life in patients with multiple sclerosis. Disabil Rehabil 2014;36:732-6.

83 Mikula P, Nagyova I, Krokavcova M, et al. The mediating effect of coping on the association between fatigue and quality of life in patients with multiple sclerosis. Psychol Health Med 2015;20:653-61.

84 Mikula P, Nagyova I, Krokavcova M, et al. Do coping strategies mediate the association between type $\mathrm{D}$ personality and quality of life among people with multiple sclerosis? J Health Psychol 2018;23:1557-65.

85 Van Damme S, De Waegeneer A, Debruyne J. Do flexible goal adjustment and acceptance help preserve quality of life in patients with multiple sclerosis? Int J Behav Med 2016;23:333-9.

86 Nery-Hurwit M, Yun J, Ebbeck V. Examining the roles of selfcompassion and resilience on health-related quality of life for individuals with multiple sclerosis. Disabil Health J 2018;11:256-61.

87 Koelmel E, Hughes AJ, Alschuler KN, et al. Resilience mediates the longitudinal relationships between social support and mental health outcomes in multiple sclerosis. Arch Phys Med Rehabil 2017:98:1139-48.

88 Wilski M, Tasiemski T. Health-Related quality of life in multiple sclerosis: role of cognitive appraisals of self, illness and treatment. Qual Life Res 2016;25:1761-70.

89 Calandri E, Graziano F, Borghi M, et al. Depression, positive and negative affect, optimism and health-related quality of life in recently diagnosed multiple sclerosis patients: the role of identity, sense of coherence, and self-efficacy. J Happiness Stud 2018;19:277-95.

90 Mikula P, Nagyova I, Krokavcova M, et al. Self-Esteem, social participation, and quality of life in patients with multiple sclerosis. $J$ Health Psychol 2017;22:984-92.

91 Valvano A, Floyd RM, Penwell-Waines L, et al. The relationship between cognitive fusion, stigma, and well-being in people with multiple sclerosis. J Contextual Behav Sci 2016;5:266-70.

92 Costa DC, Sá MJ, Calheiros JM. Social support network and quality of life in multiple sclerosis patients. Arq Neuropsiquiatr 2017;75:267-71 https://doi.org/

93 Mikula P, Nagyova I, Krokavcova M, et al. Social participation and health-related quality of life in people with multiple sclerosis. Disabil Health J 2015;8:29-34.

94 Chiu C-Y, Chan F, Edward Sharp S, Edward S, et al. Employment as a health promotion intervention for persons with multiple sclerosis. Work 2015;52:749-56. 
95 Possa MF, Minacapelli E, Canale S, et al. The first year after diagnosis: psychological impact on people with multiple sclerosis. Psychol Health Med 2017;22:1063-71.

96 Stern BZ, Strober L, DeLuca J, et al. Subjective well-being differs with age in multiple sclerosis: a brief report. Rehabil Psychol 2018;63:474-8.

97 Calandri E, Graziano F, Borghi M, et al. Coping strategies and adjustment to multiple sclerosis among recently diagnosed patients: the mediating role of sense of coherence. Clin Rehabil 2017;31:1386-95.

98 Nourbakhsh B, Julian L, Waubant E. Fatigue and depression predict quality of life in patients with early multiple sclerosis: a longitudinal study. Eur J Neurol 2016;23:1482-6.

99 Buhse M, Banker WM, Clement LM. Factors associated with healthrelated quality of life among older people with multiple sclerosis. Int J MS Care 2014;16:10-19.

100 Kinkel RP, Laforet G, You X. Disease-Related determinants of quality of life 10 years after clinically isolated syndrome. Int $J$ MS Care 2015;17:26-34.

101 Bueno A-M, Sayao A-L, Yousefi M, et al. Health-related quality of life in patients with longstanding 'benign multiple sclerosis'. Mult Scler Relat Disord 2015;4:31-8.

102 Baumstarck K, Pelletier J, Boucekine M, et al. Predictors of quality of life in patients with relapsing-remitting multiple sclerosis: a 2-year longitudinal study. Rev Neurol 2015;171:173-80.

103 Tepavcevic DK, Pekmezovic T, Stojsavljevic N, et al. Change in quality of life and predictors of change among patients with multiple sclerosis: a prospective cohort study. Qual Life Res 2014;23:1027-37.

104 Chruzander C, Ytterberg C, Gottberg K, et al. A 10-year follow-up of a population-based study of people with multiple sclerosis in Stockholm, Sweden: changes in health-related quality of life and the value of different factors in predicting health-related quality of life. J Neurol Sci 2014;339:57-63.

105 Young J, Amatya B, Galea MP, et al. Chronic pain in multiple sclerosis: a 10-year longitudinal study. Scand J Pain 2017:16:198-203.

106 Carletto S, Tesio V, Borghi M, et al. The effectiveness of a BodyAffective mindfulness intervention for multiple sclerosis patients with depressive symptoms: a randomized controlled clinical trial. Front Psychol 2017;8:1-13.

107 Besharat M, massood Nabavi S, Geranmayepour S, et al. Mindfulness-based stress reduction (MBSR) program: the effect of a novel Psycho-interventional method on quality of life, mental health, and self-efficacy in female patients with multiple sclerosis: a randomized clinical trial. J.jbtw 2017;06:211-5.

108 Blankespoor RJ, Schellekens MPJ, Vos SH, et al. The effectiveness of Mindfulness-Based stress reduction on psychological distress and cognitive functioning in patients with multiple sclerosis: a pilot study. Mindfulness 2017;8:1251-8.

109 Simpson R, Mair FS, Mercer SW. Mindfulness-based stress reduction for people with multiple sclerosis - a feasibility randomised controlled trial. BMC Neurol 2017;17:1-12.

110 Spitzer E, Pakenham KI. Evaluation of a brief community-based mindfulness intervention for people with multiple sclerosis: a pilot study. Clin Psychol 2018;22:182-91.

111 Ghodspour Z, Najafi M, Rahimian Boogar I. Effectiveness of Mindfulness-Based cognitive therapy on psychological aspects of quality of life, depression, anxiety, and stress among patients with multiple sclerosis. Pract. Clin. Psychol. 2018;6:215-22.

112 Case LK, Jackson P, Kinkel R, et al. Guided imagery improves mood, fatigue, and quality of life in individuals with multiple sclerosis: an exploratory efficacy trial of healing light guided imagery. J Evid Based Integr Med 2018;23:2515690X1774874-8.

113 Blair M, Ferreria G, Gill S, et al. Dialectical behavior group therapy is feasible and reduces emotional dysfunction in multiple sclerosis. Int $J$ Group Psychother 2017;67:500-18.

114 Calandri E, Graziano F, Borghi M, et al. Improving the quality of life and psychological well-being of recently diagnosed multiple sclerosis patients: preliminary evaluation of a groupbased cognitive behavioral intervention. Disabil Rehabil 2017;39:1474-81.

115 Graziano F, Calandri E, Borghi M, et al. The effects of a group-based cognitive behavioral therapy on people with multiple sclerosis: a randomized controlled trial. Clin Rehabil 2014;28:264-74.

116 Kiropoulos LA, Kilpatrick T, Holmes A, et al. A pilot randomized controlled trial of a tailored cognitive behavioural therapy based intervention for depressive symptoms in those newly diagnosed with multiple sclerosis. BMC Psychiatry 2016;16:1-10.

117 Chruzander C, Gottberg K, Ytterberg C, et al. A single-group pilot feasibility study of cognitive behavioural therapy in people with multiple sclerosis with depressive symptoms. Disabil Rehabil 2016:38:2383-91.

118 Kikuchi H, Niino M, Hirotani M, et al. Pilot study on the effects of cognitive behavioral therapy on depression among Japanese patients with multiple sclerosis. Clin Exp Neuroimmunol 2019;10:180-5.

119 Pakenham KI, Mawdsley M, Brown FL, et al. Pilot evaluation of a resilience training program for people with multiple sclerosis. Rehabil Psychol 2018;63:29-42.

120 Proctor BJ, Moghaddam NG, Evangelou N, et al. Telephonesupported acceptance and commitment bibliotherapy for people with multiple sclerosis and psychological distress: a pilot randomised controlled trial. Journal of Contextual Behavioral Science 2018;9:103-9.

121 Abolghasemi abbas, Taherifard M, Farhang S, et al. The effect of supportive-expressive therapy on hope and quality of life in patients with multiple sclerosis (MS). Archives of Psychiatry and Psychotherapy 2016;18:20-7.

122 Jongen P, Ruimschotel R, Heerings M, et al. Improved self-efficacy in persons with relapsing remitting multiple sclerosis after an intensive social cognitive wellness program with participation of support partners: a 6-months observational study. Health Qual Life Outcomes 2014;12:40-9.

123 Jongen PJ, Heerings M, Ruimschotel R, et al. Intensive social cognitive treatment (can do treatment) with participation of support partners in persons with relapsing remitting multiple sclerosis: observation of improved self-efficacy, quality of life, anxiety and depression 1 year later. BMC Res Notes 2016;9:1-8.

124 Eliášová A, Majerníková L'udmila, Hudáková A, et al. Self-help group and the quality of life of patients with multiple sclerosis - Pilot study. Cent Eur J Nurs Midw 2015;6:336-42.

125 Liu Y. A hope-based group therapy program to women with multiple sclerosis: quality of life. NeuroQuantology 2017;15:127-32.

126 Mulligan $\mathrm{H}$, Wilkinson A, Barclay A, et al. Evaluation of a fatigue self-management program for people with multiple sclerosis. Int $J$ MS Care 2016;18:116-21.

127 Thomas PW, Thomas S, Kersten P, et al. One year follow-up of a pragmatic multi-centre randomised controlled trial of a group-based fatigue management programme (facets) for people with multiple sclerosis. BMC Neurol 2014;14:1-6.

128 Ehde DM, Elzea JL, Verrall AM, et al. Efficacy of a TelephoneDelivered self-management intervention for persons with multiple sclerosis: a randomized controlled trial with a one-year follow-up. Arch Phys Med Rehabil 2015;96:1945-58.

129 Feicke J, Spörhase U, Köhler J, et al. A multicenter, prospective, quasi-experimental evaluation study of a patient education program to foster multiple sclerosis self-management competencies. Patient Educ Couns 2014;97:361-9.

130 LeClaire K, Cecil A, LaRussa A, et al. Short Report: A Pilot Study of a Group Positive Psychology Intervention for Patients with Multiple Sclerosis. Int J MS Care 2018;20:136-41.

131 Geiser F, Imbierowicz K, Conrad R, et al. [Differences between patients classified as "recovered" or "improved" and "unchanged" or "deteriorated" in a psychotherapy outcome study]. Z Psychosom Med Psychother 2001;47:250-61. 